\title{
Ordered Solvents and Ionic Liquids Can be Harnessed for Electrostatic Ca-
} talysis

\author{
Longkun Xu, ${ }^{1}$ Ekaterina I. Izgorodina, ${ }^{2 *}$ Michelle L. Coote ${ }^{1^{*}}$
}

1 ARC Centre of Excellence for Electromaterials Science, Research School of Chemistry, Australian National University, Canberra, Australian Capital Territory, 2601, Australia

2 Monash Computational Chemistry Group, School of Chemistry, Monash University, 17 Rainforest Walk, Clayton, Victoria 3800, Australia

ABSTRACT: Herein we employ classical molecular dynamics simulations using the Drude oscillator based polarizable force field, quantum chemical calculations, and ONIOM multiscale calculations to study a) how an external field orders the solvent environment in a chemical reaction and then b) whether, in the absence of this same applied field, the ordered solvent environment alone can electrostatically catalyse a chemical reaction when compared with the corresponding disordered solvent. Our results show that a $0.2 \mathrm{~V} / \AA ̊$ external electric field, which is below the threshold for bond breaking of solvent molecules, leads to significant ordering of bulk methanol solvent and the ionic liquid [EMIM][BF ${ }_{4}$. Importantly, in the absence of this same field, the ordered solvent lowers the activation energy of the hydrogen-transfer reaction of o-alkylphenyl ketones in excess of $20 \mathrm{kcal} / \mathrm{mol}$ when the solvent is methanol, and by over $30 \mathrm{kcal} / \mathrm{mol}$ for [EMIM][BF 4 ]. Even a $0.1 \mathrm{~V} / \AA ̊$ external field has effects of ca. 10 and $20 \mathrm{kcal} / \mathrm{mol}$ respectively. This work suggests a possible strategy for scaling electrostatic catalysis by applying a pulsed external field to the reaction medium to maintain solvent ordering, while allowing the reaction to proceed largely in the absence of an external field.

\section{INTRODUCTION}

The role of the electrostatic environment in catalysing chemical reactions has long been an important research field. Two classical examples are Marcus theory ${ }^{1,2}$ and enzyme catalysis. ${ }^{3-6}$ In Marcus theory, solvent reorganization is the driving force for electron-transfer reactions, though internal reorganization can also be large. One of the explanations for enzyme catalysis is that the enzyme can stabilize the polar transition state via electrostatic interactions. . $^{3,7}$

In recent years, much research has been directed at harnessing electric fields for catalysing and manipulating chemical reactions beyond enzymes. ${ }^{8-10}$ While much of this work has been computational, experiments have shown that external electric fields (EEFs) delivered via scanning tunnelling microscopy (STM) can catalyse bond forming ${ }^{11}$ and bond breaking reactions. ${ }^{12}$ While these experiments are difficult to scale for chemical synthesis, we have shown that the electric fields from remote charged functional groups, embedded on the substrate or a catalyst, can be used to catalyse chemical reactions and alter their outcome..$^{13-25}$ The charged group can be a Lewis acid, or an acid or base, whose charge and hence electric field, can be altered with $\mathrm{pH}$. While again much of the work to date has been computational, experiments have validated these predictions in a growing number of systems. ${ }^{17-20,26,27}$ Others have shown that electrostatic effects are responsible for the catalytic effect of metal ion clusters on gas-phase reactions ${ }^{28-30}$ and that electrostatic effects are of general importance in heterogeneous catalysis. $^{31}$

Despite these advances, there remain fundamental barriers to taking full advantage of electrostatic catalysis. On the one hand, the use of charged groups is an effective and scalable way to exert very precise electrostatic control over chemical reactions. However, the magnitude of such effects can be compromised by solvent attenuation, particularly as the solubility of charged species in low polarity solvents is often low. Use of external electric fields avoids solubility issues but STM experiments are very small in scale, while scale-up using electrodes has thus far 
resulted in electrochemical reactions. ${ }^{12}$ While these may be useful in their own right, ${ }^{32}$ and while the electric fields undoubtedly influence the electrochemical processes themselves, ${ }^{33,}, 34$ the use of external fields to afford significant electrostatic catalysis in solution is yet to be realised.

To use external electric fields for electrostatic catalysis alternative approaches are required. One such approach is to use external fields to orient the solvent environment. The ordering of the solvent and ionic liquids (ILS) induced by external electric field has already been reported by several groups. For example, Foroutan-Nejad and coworkers found EEFs can break the solvation shell and thus affect the ion-receptor interactions. ${ }^{35}$ Laird and co-workers reported that the structure of the solvent framework and associated dielectric properties can be changed by an electric field. ${ }^{36}$ Matta and co-workers showed that the electric field of a laser pulse can be used to eliminate (or even invert) a potential energy barrier of a reaction. 37,38 The ordering of the network of ionic liquids, which offer many advantages, ${ }^{39-41}$ can also be changed by factors including electric field, temperature, the length of the side chain of cations and metal surfaces, as shown by Wang, Voth and Pádua. ${ }^{42-45}$

Recent computational work has shown that external fields can both order the solvent environment and catalyse chemical reactions. ${ }^{46-50}$ However, given the propensity for external electric fields to trigger electrochemical reactions, a more practical question is whether, in the absence of a field, local electric fields within the ordered solvent environment itself are sufficient to catalyse a chemical reaction. Thus, solvents could be pre-ordered with a field and then reactions would be allowed to proceed without the external electric present. This could be carried out by pulsing the applied potential, thereby minimising exposure to the external potential. While in a normal electrochemical cell the potential beyond the double layer is negligible, bipolar cells ${ }^{51}$ could address this problem. Or indeed, solvents could be pre-ordered in other ways such as using microfluidics.
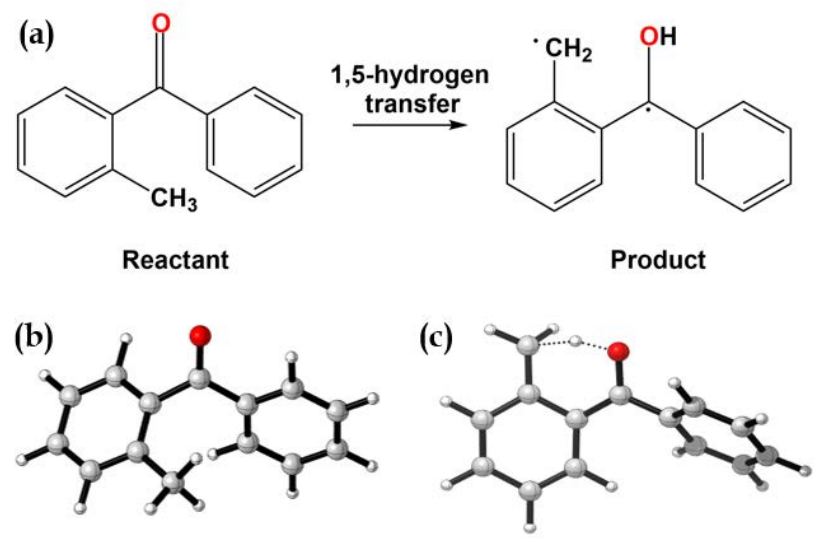

EEF

Figure 1. The scheme (a) of hydrogen-transfer reaction of o-alkylphenyl ketones. The optimized structures of reactant (b) and transition state (c) of this reaction and the direction of the EEF. For more details of the reaction, see Ref. ${ }^{24}$ The structures are rendered using CYLview program. ${ }^{52}$

In this work, we use both Drude oscillator based polarizable classical molecular dynamic (MD) simulations and multiscale quantum chemical calculations to determine if an ordered solvent environment is enough to catalyse a chemical reaction in the absence of an applied electric field. As a case study, we examine a hydrogen-transfer reaction of o-alkylphenyl ketones taken from our recent work (Figure 1). ${ }^{24}$ We consider two solvent environments, methanol and the ionic liquid [EMIM] $\left[\mathrm{BF}_{4}\right]$, where EMIM is the 1-Ethyl-3-methylimidazolium cation.

\section{RESULTS AND DISCUSSION}

Classical molecular dynamics simulations using the Drude oscillator based polarizable force field, ${ }^{53-55}$ quantum chemical calculations, and ONIOM multiscale calculations were used to study the ordering effect of an external field on the solvent environment in a chemical reaction, and the effect of this solvent environment in the absence of the applied field. Figure 2 shows the general workflow used to order the solvent in the electric field and simulate its effects on the reaction in Figure 1. Full computational procedures and parameters are provided in Supporting Information. 


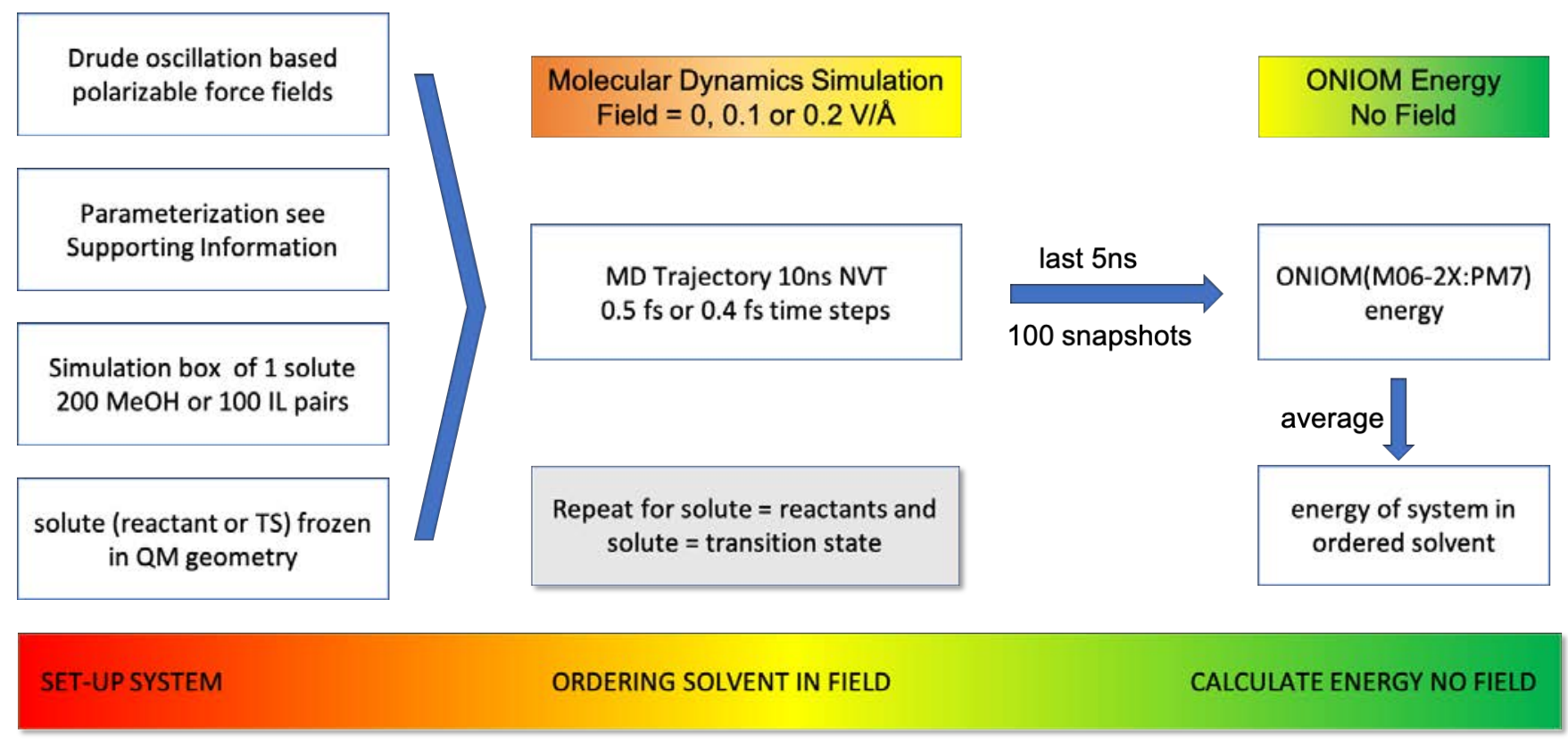

Figure 2. The workflow to calculate the activation energies. The CL\&Pol (KSDrude) force field ${ }^{56-58}$ was used for the ionic liquid (IL) and OPLS-AA force field ${ }^{59}$ for the methanol and solute. Force-field parameters and polarizabilities were taken from the literature and/or calculated using published methods ${ }^{60-66}$ and are provided in Tables S1-S6 of the Supporting Information. The simulation box, with periodic boundary conditions, initially has a size of $25 \AA$ and $34 \AA$ for methanol and the IL, respectively. Molecular dynamics simulations are performed using the Nosé-Hoover thermostat and barostat, with time steps of $0.5 \mathrm{fs}$ and $0.4 \mathrm{fs}$ for simulations in methanol and [EMIM] [BF 4 respectively. From the last 5 ns NVT simulations we extract 100 snapshots using the cut function of Travis program. ${ }^{67}$ The energy in each snapshot is calculated with $\mathrm{ONIOM}^{68}\left(\mathrm{MO62X}^{69} / \mathrm{def}^{-}-\mathrm{TZVPP}^{70}: \mathrm{PM}^{71}\right)$. The number of snapshots required to obtain an accurate barrier height is determined by benchmarking using high-level quantum chemical results obtained with methods presented in Ref. ${ }^{72-75}$. Full details of all calculations are in the Supporting Information.

Effect of External Fields on the Solvent Environment. To visualize how the environment is ordered under the influence of external electric field, the representative snapshots obtained with MD simulation of TS solute in methanol solvent and [EMIM] $\left[\mathrm{BF}_{4}\right]$ ionic liquids under 0 and 0.2 $\mathrm{V} / \AA ̊ \AA$ electric field are shown in Figure 3.

It can be seen from Figure 3 that the distribution of methanol solvent molecules in the simulation box changes obviously after $0.2 \mathrm{~V} / \AA$ A external electric field is applied. In Figure 3(a), methanol solvent molecules are distributed randomly. While in Figure 3(b), most $\mathrm{O}$ atoms of methanol, point to the right because the external electric field is pointing to the left and the $\mathrm{O}$ atoms have negative partial charge. Conversely, the methyl groups which have a positive partial charge point in the opposite direction.
Thus, the internal electric field runs from left to right, opposite to that of external electric field.

In contrast, the change of the distribution of [EMIM] $\left[\mathrm{BF}_{4}\right]$ resulted from the external electric field is less obvious. One possible reason is that ionic liquids environment has two types of molecules (cation and anion). Unlike methanol molecules, the cations and anions move independently of one another. Besides, cations and anions can form strong electrostatic interactions with their near neighbours that drown out higher-level ordering. This competition between external electric field and the electrostatic interactions between ions can also be found in the work of Wang. ${ }^{44}$ The use of stronger fields can overcomes this, ${ }^{44}$ however, because the bonds of 

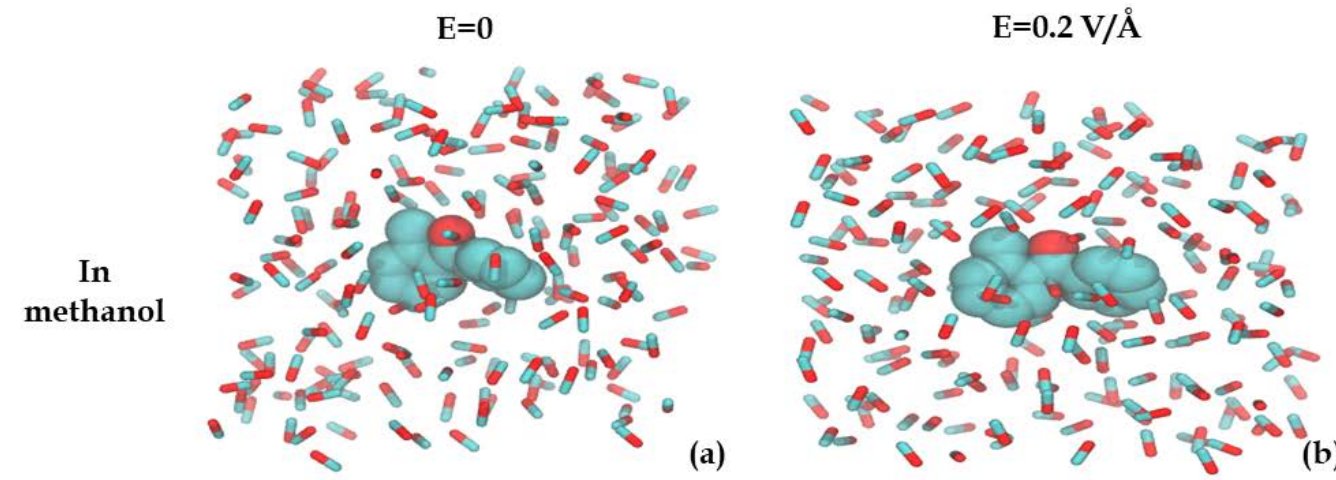

External Electric Field

a)

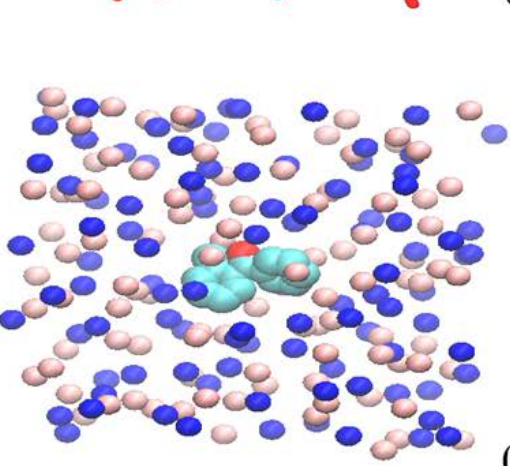

(b)
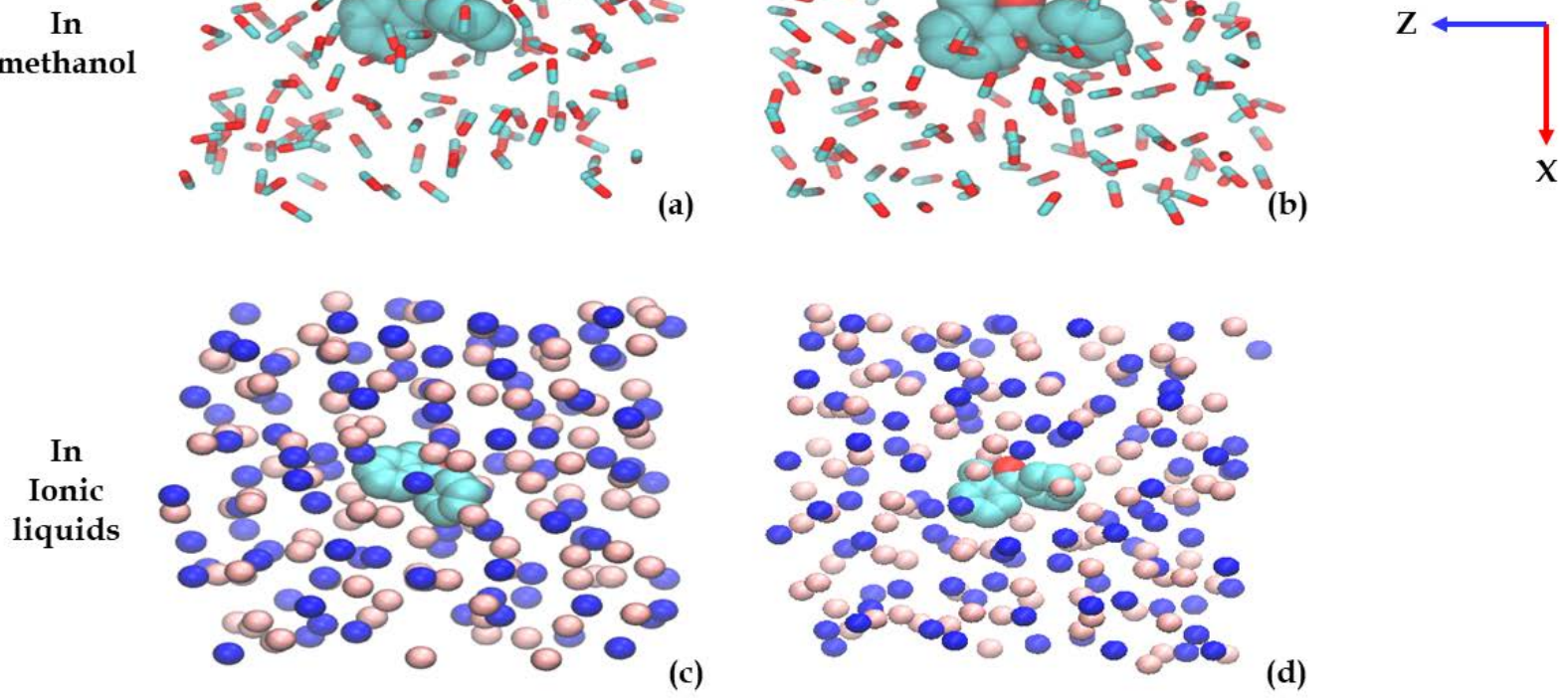

Figure 3. Snapshots obtained without and with $0.2 \mathrm{~V} / \AA$ external electric field of the TS solute molecule in methanol ((a) and $(b))$ and in [EMIM] $\left[\mathrm{BF}_{4}\right]$ ionic liquids ((c) and (d)). For clarity, only non-hydrogen atoms of the solute molecule are shown in VDW drawing method. Only C (in green) and O (in red) atoms of methanol molecules ((a) and (b)) are shown. Only N (in blue, atom N3 in Figure 4(d) below) and B (in pink) atoms representing the mass centres of respectively cations and anions of [EMIM] $\left[\mathrm{BF}_{4}\right]$ ionic liquids $((\mathrm{c})$ and $(\mathrm{d}))$ are shown. All pictures are rendered using VMD program ${ }^{76}$. The external electric field is applied along the $z$ direction.

methanol solvent might be broken under higher electric field, ${ }^{77}$ as reported by Saitta and co-workers, we do not consider electric fields larger than $0.2 \mathrm{~V} / \AA$ for all environments.

Although the ordering of ionic liquids is less obvious, it can be confirmed by the results of radial distribution function (RDF) in Figure 4. The RDF in normal and ordered ionic liquids are obtained using Travis program. ${ }^{67}$ Only the distance from 0 to $1700 \mathrm{pm}$ are shown here. Full details can be found in Table S8. The distance between the cation and the nearest anion is around $500 \mathrm{pm}$, but the radial distribution function $g(r)$ obtained in normal ionic liquids is much larger than that in ordered ionic liquids. This can be explained by comparing the simplified structures of normal and ordered ionic liquids in Figure 4(b) and (c). In normal ionic liquids, the cations and anions usually form the alternative charge structures, like Figure 4(b), as shown in Figure 2 of the work of Izgorodina and co-workers. ${ }^{78}$ When an external electric field is applied, the structure can be changed to Figure4(c) where closer cationcation and anion-anion distances become possible. The most classical example for this is probably the electrochemical double-layer, for example, see Figure 3 in the work of Sharma and co-worker ${ }^{79}$ This point has been also discussed in the works of Kaneko ${ }^{80}$ and Kornyshev ${ }^{81}$. With the change from normal ionic liquids to ordered ionic liquids, the closer cation-cation and anion-anion pairs become possible, thus the number of nearest cation-anion pairs decreases. Thus, our calculated RDF in Figure 4(a) indicates the ordering of ionic liquids does happen although it is less obvious in Figure 3(d). 


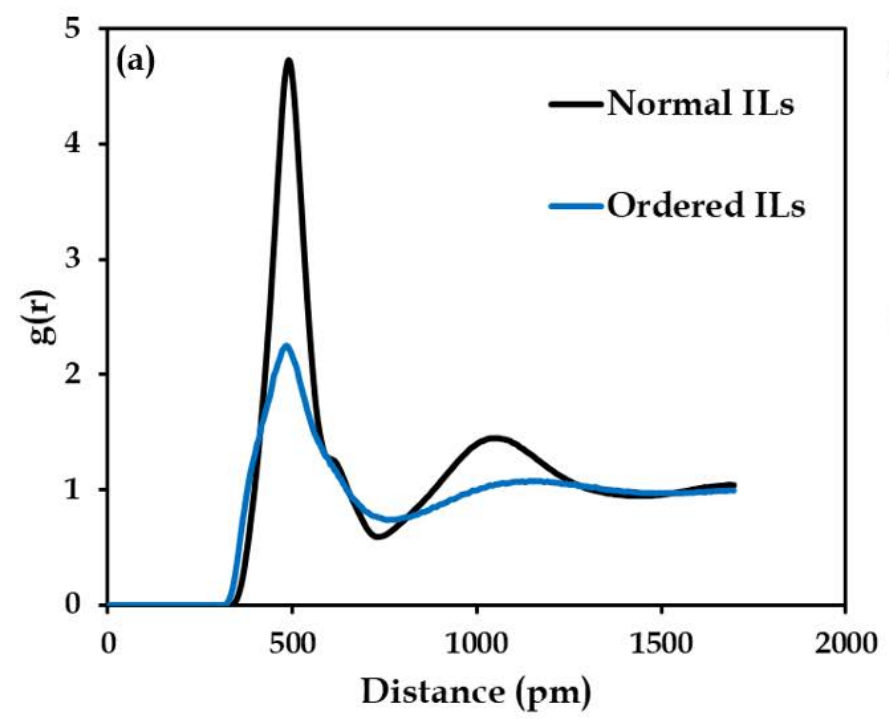

(b)

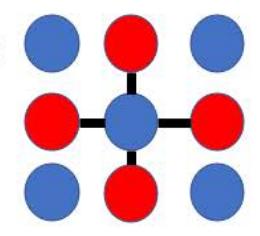

(c)

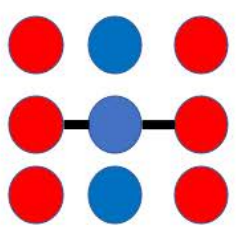

(e)
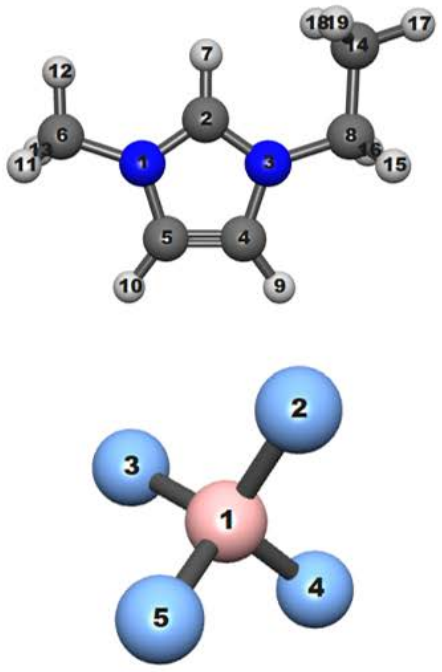

Figure 4. (a) Radial distribution function (RDF) between [EMIM] $\mathrm{C} 2$ atoms and $\left[\mathrm{BF} \mathrm{F}_{4}\right] \mathrm{B} 1$ atoms in normal and ordered ionic liquids. (b) and (c) respectively a simplified model of normal ionic liquids and ordered ionic liquids where the interactions between the centre cation and nearest anion are labelled. (d) and (e) respectively the structure of cation and anion and their atomic index, pictures are rendered using $1 Q \mathrm{~mol}$ program ${ }^{82}$.

Effect of Ordered Solvent Environment on Reactions. Figure 5 shows the activation energy in normal and ordered environment. We again stress that these species are calculated without the external field present; the field strength refers to that used to order the solvent environment. The energy used to calculate activation energy is obtained by averaging the ensemble of snapshots (full details can be found in Table S9-S10).

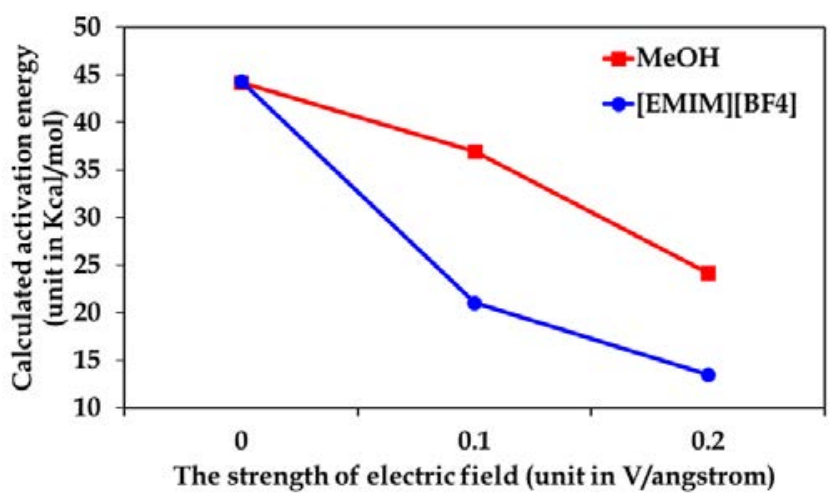

Figure 5. Calculated activation energy obtained in methanol solvent and the ionic liquid [EMIM] $\left[\mathrm{BF}_{4}\right]$ without external electric field, as a function of the field strength used to order the surrounding solvent environment.

From Figure 5 we can see the activation energy in both methanol solvent and [EMIM] $\left[\mathrm{BF}_{4}\right]$ ionic liquids are decreased in the presence of the ordered solvent environment. In methanol, the activation energy changes substantially from $44.20 \mathrm{kcal} \mathrm{mol}^{-1}$ in normal methanol solvent to $36.96 \mathrm{kcal} \mathrm{mol}^{-1}$ in ordered methanol solvent formed by $0.1 \vee \AA^{-1}$ electric field and then change to $24.19 \mathrm{kcal} / \mathrm{mol}$ in ordered methanol solvent formed by $0.2 \mathrm{~V}^{-1}$ electric field. Similarly, the obtained activation energy decreases from $44.34 \mathrm{kcal} \mathrm{mol}^{-1}$ in normal disordered ionic liquids to 21.03 and $13.49 \mathrm{kcal} \mathrm{mol}^{-1}$ in ordered ionic liquids formed by respectively 0.1 and $0.2 \mathrm{~V}$ $\AA^{-1}$ external electric field.

The electrostatic origin of the barrier-lowering is evident in Figure 6, which shows representative snapshots from the MD simulation without and with the $0.2 \mathrm{~V} \AA^{-1}$ electric field. Also shown are the corresponding dipole moments of the system and the reaction axis. ${ }^{9}$ The reaction axis is the direction along which the electrons reorganize from reactant-like to product-like bonding (in this case the local dipole moment across the forming and breaking bonds). A field aligned parallel but opposite to the reaction axis stabilizes the transition state. Without an external electric field, solvent molecules are randomly distributed, and the dipole moment is almost is perpendicular to the reaction axis. With the external electric field, the dipole moment is larger, its direction is nearly parallel to the reaction axis and its polarity is primed to stabilize transition state, hence accounting for the barrier lowering observed. 


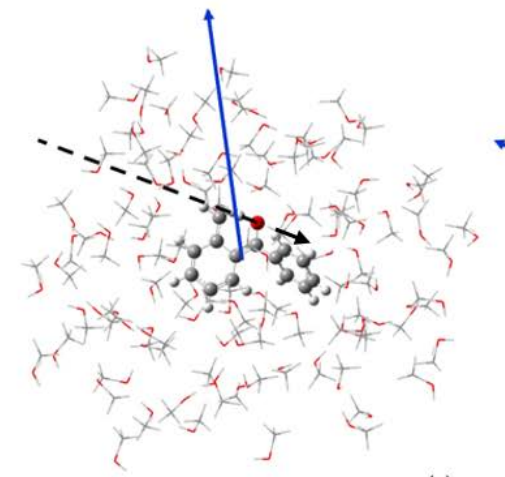

(a)

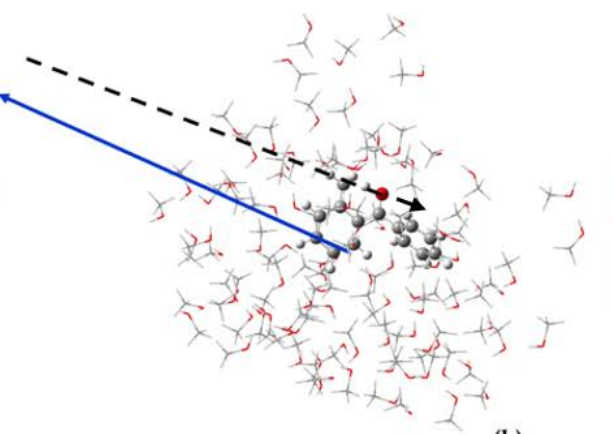

(b)

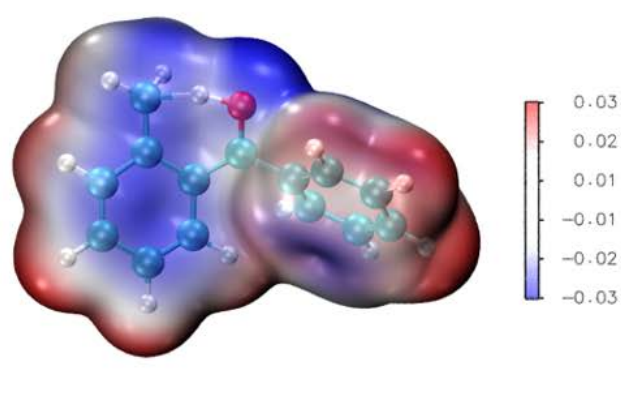

(c)

Figure 6. Representative snapshots from the MD simulation (a) without and (b) with $0.2 \mathrm{~V} \AA^{-1}$ electric field. The dipole moment direction is in blue while the black dashed line represents the reaction axis. ${ }^{9}$ Note that the length of the blue line in (b) has been scaled; the magnitude of the dipole moment in (b), 146.46 Debye, is over four times of that of (a), 37.06 Debye. (c) The electrostatic potential (unit in a.u.) within the isolated transition state, as calculated in continuum water.

We note that the actual activation barrier decrease measured from experiment might be smaller than that we calculate. The reasons are two-fold. First, in our MD simulation, the external electric field is identically applied to all particles in the system while the electric field strength felt by different particles in experimental electrochemical cell should be different and depend on the distance from the charged electrodes. However, as noted in the introduction the use of bipolar electrochemical cells could address this problem.

Second, we assume the solvent remains ordered through the whole reaction process. The relaxation from ordered solvent to normal disordered solvent is ignored. Thus, a time-dependent non-equilibrium simulation should give more accurate results. However, these are beyond scope of the present work. Instead, we note that experimental studies report that liquid solvents such as methanol relax on the order of 0.1 to $10 \mathrm{ps},{ }^{83}$ which is faster than the timescale of our reaction. However, for ionic liquids relaxation times are slower, and can tuned be through cation and anion choice. Typically, relaxation times of the order of $1 \mathrm{~s}$ are observed over temperature ranges of 300$330 \mathrm{~K},{ }^{84,85}$ but longer times of up to 100 s are frequently reported. ${ }^{86}$ These are longer than the corresponding halflife the reaction studied here in the ordered ionic liquid $\left(10^{2}-10^{1} \mathrm{~s}\right.$ at $0.1 \mathrm{~V} \AA^{-1}$ and $10^{-3}-10^{-4} \mathrm{~s}$ at $0.2 \mathrm{~V} \AA^{-1}$ for 300 and $330 \mathrm{~K}$ respectively).

\section{CONCLUSION}

Summing up, we propose a new strategy for electrostatic catalysis. Using ordered solvent and ionic liquids to catalyse reactions is environmentally friendly and can effectively solve the solvent-attenuation problem in current electrostatic catalysis. Results of the hydrogen-transfer reaction of o-alkylphenyl ketones obtained by combining polarizable classical MD simulation with ONIOM energy calculation indicate that both ordered methanol solvent and $[\mathrm{EMIM}]\left[\mathrm{BF}_{4}\right]$ ionic liquids can help decrease activation energy significantly. Using larger electric field strengths can make the environment more ordered, which provides stronger electrostatic catalysis effects. Currently we are undertaking experimental work in our group to validate the computational predictions. However, tentative experimental support for our work comes from the results of Slattery and co-workers, who showed that liquid-crystalline ionic liquids (ICILs) can work as an ordered reaction medium driven by the temperature change to change the exo/endo ratio of the Diels-Alder reaction. ${ }^{87}$ More generally, our work suggests that electrostatic effects on solution-phase catalysis should not be ignored when studying other ordered environments such as at electrochemical interfaces or in nanoconfined environments.

\section{ASSOCIATED CONTENT}

Supporting Information All computational procedures along with details of the parameters, determination of the suitable number of snapshots, benchmarking, raw data used in calculating RDF, energy calculated in each snapshot. The Supporting Information is available free of charge on the ACS Publications website.

\section{AUTHOR INFORMATION}

Corresponding Author 
*Email: michelle.coote@anu.edu.au; Phone: 6126125 3771; (M.L.C.)

*Email: katya.pas@monash.edu; (E.I.I.)

\section{Author Contributions}

The manuscript was written through contributions of all authors. All authors have given approval to the final version of the manuscript.

\section{ACKNOWLEDGMENT}

The authors acknowledge an ARC Laureate Fellowship (to M.L.C.), and generous supercomputing time from the National Computational Infrastructure. The authors acknowledge helpful discussions with Peter Halat, Michael Robinson, Luke Wylie, Dr. Axel Kohlmeyer, Dr. Zhenxing Wang, Mitchell Blyth, Dr. Li-Juan Yu, Hugo Macdermott-Opeskin, Dr. Tian Lu, Prof. Agílio A. H. Pádua and Kateryna Goloviznina.

Funding Sources

Australian Research Council (FL170100041)

\section{REFERENCES}

1. Marcus, R. A., On the Theory of Oxidation-Reduction Reactions Involving Electron Transfer .1. J. Chem. Phys. 1956, 24, 966-978.

2. Ghosh, S.; Horvath, S.; Soudackov, A. V.; HammesSchiffer, S., Electrochemical Solvent Reorganization Energies in the Framework of the Polarizable Continuum Model. J. Chem. Theory Comput. 2014, 10, 2091-2102.

3. Warshel, A.; Sussman, F., Toward computer-aided sitedirected mutagenesis of enzymes. Proc. Natl. Acad. Sci. U. S. A. 1986, 83, 3806-3810.

4. $\quad$ Warshel, A.; Sharma, P. K.; Kato, M.; Xiang, Y.; Liu, H.; Olsson, M. H., Electrostatic basis for enzyme catalysis. Chem. Rev. 2006, 106, 3210-3235.

5. Fried, S. D.; Boxer, S. G., Electric Fields and Enzyme Catalysis. Annu Rev Biochem 2017, 86, 387-415.

6. Romei, M. G.; Lin, C. Y.; Mathews, I. I.; Boxer, S. G., Electrostatic control of photoisomerization pathways in proteins. Science 2020, 367, 76-+.

7. Wu, Y.; Fried, S. D.; Boxer, S. G., A Preorganized Electric Field Leads to Minimal Geometrical Reorientation in the Catalytic Reaction of Ketosteroid Isomerase. J. Am. Chem. Soc. 2020, 142, 9993-9998.

8. $\quad$ Ciampi, S.; Darwish, N.; Aitken, H. M.; Díez-Pérez, I.; Coote, M. L., Harnessing electrostatic catalysis in single molecule, electrochemical and chemical systems: a rapidly growing experimental tool box. Chem. Soc. Rev. 2018, 47, 5146-5164.

9. Shaik, S.; Ramanan, R.; Danovich, D.; Mandal, D., Structure and reactivity/selectivity control by oriented-external electric fields. Chem. Soc. Rev. 2018, 47, 5125-5145.

10. Shaik, S.; Mandal, D.; Ramanan, R., Oriented electric fields as future smart reagents in chemistry. Nat. Chem. 2016, 8, 1091-1098.

11. Aragones, A. C.; Haworth, N. L.; Darwish, N.; Ciampi, S.; Bloomfield, N. J.; Wallace, G. G.; Diez-Perez, I.; Coote, M. L., Electrostatic catalysis of a Diels-Alder reaction. Nature 2016, 531, 88-91.
12. Zhang, L.; Laborda, E.; Darwish, N.; Noble, B. B.; Tyrell, J. H.; Pluczyk, S.; Le Brun, A. P.; Wallace, G. G.; Gonzalez, J.; Coote, M. L., Electrochemical and electrostatic cleavage of alkoxyamines. J. Am. Chem. Soc. 2018, 140, 766-774.

13. Gryn'ova, G.; Coote, M. L., Origin and Scope of LongRange Stabilizing Interactions and Associated SOMO-HOMO Conversion in Distonic Radical Anions. J. Am. Chem. Soc. 2013, 135, 15392-15403

14. Blyth, M. T.; Coote, M. L., A pH-Switchable Electrostatic Catalyst for the Diels-Alder Reaction: Progress toward Synthetically Viable Electrostatic Catalysis. J. Org. Chem. 2019, 84, 1517-1522.

15. Hill, N. S.; Coote, M. L., Internal Oriented Electric Fields as a Strategy for Selectively Modifying Photochemical Reactivity. J. Am. Chem. Soc. 2018, 140, 17800-17804.

16. Yu, L. J.; Coote, M. L., Electrostatic Switching between S(N)1 and S(N)2 Pathways. J. Phys. Chem. A 2019, 123, 582-589.

17. Gryn'Ova, G.; Marshall, D. L.; Blanksby, S. J.; Coote, M. L., Switching radical stability by $\mathrm{pH}$-induced orbital conversion. Nat. Chem. 2013, 5, 474

18. Noble, B. B.; Smith, L. M.; Coote, M. L., The effect of LiNTf 2 on the propagation rate coefficient of methyl methacrylate. Polym. Chem. 2014, 5, 4974-4983.

19. Noble, B. B.; Mater, A. C.; Smith, L. M.; Coote, M. L., The effects of Lewis acid complexation on type I radical photoinitiators and implications for pulsed laser polymerization. Polym. Chem. 2016, 7, 6400-6412.

20. Gryn'ova, G.; Smith, L. M.; Coote, M. L., Computational design of $\mathrm{pH}$-switchable control agents for nitroxide mediated polymerization. Phys. Chem. Chem. Phys. 2017, 19, 22678-22683.

21. Gryn'ova, G.; Coote, M. L., Directionality and the role of polarization in electric field effects on radical stability. Aust. J. Chem. 2017, 70, 367-372.

22. Aitken, H. M.; Coote, M. L., Can electrostatic catalysis of Diels-Alder reactions be harnessed with $\mathrm{pH}$-switchable charged functional groups? Phys. Chem. Chem. Phys. 2018, 20, 1067110676.

23. Hill, N. S.; Coote, M. L., Strategies for Red-Shifting Type I Photoinitiators: Internal Electric Fields versus Lewis Acids versus Increasing Conjugation. Aust. J. Chem. 2019, 72, 627-632.

24. Blyth, M. T.; Noble, B. B.; Russell, I. C.; Coote, M. L., Oriented Internal Electrostatic Fields Cooperatively Promote Ground- and Excited-State Reactivity: A Case Study in Photochemical CO2 Capture. J Am Chem Soc 2020, 142, 606-613.

25. Joy, J.; Stuyver, T.; Shaik, S., Oriented External Electric Fields and Ionic Additives Elicit Catalysis and Mechanistic Crossover in Oxidative Addition Reactions. J. Am. Chem. Soc. 2020, 142, 38363850 .

26. Klinska, M.; Smith, L. M.; Gryn'ova, G.; Banwell, M. G.; Coote, M. L., Experimental demonstration of $\mathrm{pH}$-dependent electrostatic catalysis of radical reactions. Chem. Sci. 2015, 6, 56235627.

27. Jiang, J. Y.; Smith, L. M.; Tyrell, J. H.; Coote, M. L., Pulsed laser polymerisation studies of methyl methacrylate in the presence of $\mathrm{AlCl} 3$ and $\mathrm{ZnCl}$ 2-evidence of propagation catalysis. Polym. Chem. 2017, 8, 5948-5953.

28. Yue, L.; Li, J.; Zhou, S.; Sun, X.; Schlangen, M.; Shaik, S.; Schwarz, H., Control of product distribution and mechanism by ligation and electric field in the thermal activation of methane. Angew. Chem. Int. Ed. 2017, 56, 10219-10223.

29. Geng, C.; Li, J.; Schlangen, M.; Shaik, S.; Sun, X.; Wang, N.; Weiske, T.; Yue, L.; Zhou, S.; Schwarz, H., Oriented external electric fields as mimics for probing the role of metal ions and 
ligands in the thermal gas-phase activation of methane. Dalton Trans. 2018, 47, 15271-15277.

30. Yue, L.; Wang, N.; Zhou, S.; Sun, X.; Schlangen, M.; Schwarz, H., The electric field as a "smart" ligand in controlling the thermal activation of methane and molecular hydrogen. Angew. Chem. Int. Ed. 2018, 57, 14635-14639.

31. Che, F.; Gray, J. T.; Ha, S.; Kruse, N.; Scott, S. L.; McEwen, J.-S., Elucidating the roles of electric fields in catalysis: A perspective. ACS Catal. 2018, 8, 5153-5174.

32. Norcott, P. L.; Hammill, C. L.; Noble, B. B.; Robertson, J. C.; Olding, A.; Bissember, A. C.; Coote, M. L., TEMPO-Me: An Electrochemically Activated Methylating Agent. J. Am. Chem. Soc. 2019, 141, 15450-15455.

33. Vogel, Y. B.; Zhang, L.; Darwish, N.; Gonçales, V. R.; Le Brun, A.; Gooding, J. J.; Molina, A.; Wallace, G. G.; Coote, M. L.; Gonzalez, J., Reproducible flaws unveil electrostatic aspects of semiconductor electrochemistry. Nature Comm. 2017, 8, 1-9.

34. Zhang, L.; Vogel, Y. B.; Noble, B. B.; Goncales, V. R.; Darwish, N.; Brun, A. L.; Gooding, J. J.; Wallace, G. G.; Coote, M. L.; Ciampi, S., TEMPO monolayers on Si (100) electrodes: electrostatic effects by the electrolyte and semiconductor spacecharge on the electroactivity of a persistent radical. J. Am. Chem. Soc. 2016, 138, 9611-9619.

35. Novak, M.; Foroutan-Nejad, C.; Marek, R., Solvent effects on ion-receptor interactions in the presence of an external electric field. Phys. Chem. Chem. Phys. 2016, 18, 30754-30760.

36. Daniels, I. N.; Wang, Z. X.; Laird, B. B., Dielectric Properties of Organic Solvents in an Electric Field. J. Phys. Chem. C 2017, 121, 1025-1031.

37. Bandrauk, A. D.; Sedik, E.-W. S.; Matta, C. F., Effect of absolute laser phase on reaction paths in laser-induced chemical reactions. J. Chem. Phys. 2004, 121, 7764-7775.

38. Bandrauk, A. D.; Sedik, E. L. W. S.; Matta, C. F., Laser control of reaction paths in ion-molecule reactions. Mol. Phys. 2006, 104, 95-102.

39. Hallett, J. P.; Welton, T., Room-temperature ionic liquids: solvents for synthesis and catalysis. 2. Chem. Rev. 2011, 111, 35083576.

40. Izgorodina, E. I.; Seeger, Z. L.; Scarborough, D. L.; Tan, S. Y., Quantum chemical methods for the prediction of energetic, physical, and spectroscopic properties of ionic liquids. Chem. Rev. 2017, 117, 6696-6754.

41. Halat, P.; Seeger, Z. L.; Barrera Acevedo, S.; Izgorodina, E. I., Trends in two-and three-body effects in multiscale clusters of ionic liquids. J. Phys. Chem. B 2017, 121, 577-588.

42. Wang, Y. T.; Izvekov, S.; Yan, T. Y.; Voth, G. A., Multiscale coarse-graining of ionic liquids. J. Phys. Chem. B 2006, 110, 35643575.

43. Wang, Y.; Jiang, W.; Yan, T.; Voth, G. A., Understanding ionic liquids through atomistic and coarse-grained molecular dynamics simulations. Acc. Chem. Res. 2007, 40, 1193-1199.

44. Wang, Y. T., Disordering and Reordering of Ionic Liquids under an External Electric Field. J. Phys. Chem. B 2009, 113, 1105811060.

45. Mendonça, A. C.; Malfreyt, P.; Pádua, A. I. A., Interactions and ordering of ionic liquids at a metal surface. J. Chem. Theory Comput. 2012, 8, 3348-3355.

46. Dubey, K. D.; Stuyver, T.; Kalita, S.; Shaik, S., SolventOrganization and Rate-Regulation of a Menshutkin Reaction by Oriented-External Electric Fields are Revealed by Combined MD and QM/MM Calculations. J. Am. Chem. Soc 2020, 142, 9955-9965.
47. Herron, J. A.; Morikawa, Y.; Mavrikakis, M., Ab initio molecular dynamics of solvation effects on reactivity at electrified interfaces. Proc. Natl. Acad. Sci. U. S. A. 2016, 113, E4937-E4945.

48. Cassone, G.; Pietrucci, F.; Saija, F.; Guyot, F.; Saitta, A. M., One-step electric-field driven methane and formaldehyde synthesis from liquid methanol. Chem. Sci. 2017, 8, 2329-2336.

49. Cassone, G.; Pietrucci, F.; Saija, F.; Guyot, F.; Sponer, J.; Sponer, J. E.; Saitta, A. M., Novel electrochemical route to cleaner fuel dimethyl ether. Sci. Rep. 2017, 7, 1-9.

50. Arabi, A. A.; Matta, C. F., Effects of external electric fields on double proton transfer kinetics in the formic acid dimer. Phys. Chem. Chem. Phys. 2011, 13, 13738-13748.

51. Shida, N.; Zhou, Y.; Inagi, S., Bipolar Electrochemistry: A Powerful Tool for Electrifying Functional Material Synthesis. Acc. Chem. Res. 2019, 52, 2598-2608.

52. CYLview, 1.0b; Legault, C. Y., Université de Sherbrooke, 2009 (http://www.cylview.org) (accessed 21 May 2020).

53. Lemkul, J. A.; Huang, J.; Roux, B.; MacKerell Jr, A. D., An empirical polarizable force field based on the classical drude oscillator model: development history and recent applications. Chem. Rev 2016, 116, 4983-5013.

54. Lamoureux, G.; Roux, B., Modeling induced polarization with classical Drude oscillators: Theory and molecular dynamics simulation algorithm. J. Chem. Phys 2003, 119, 3025-3039.

55. Dequidt, A.; Devemy, J.; Padua, A. A., Thermalized Drude oscillators with the LAMMPS molecular dynamics simulator. J. Chem. Inf. Model. 2016, 56, 260-268.

56. Goloviznina, K.; Canongia Lopes, J. N.; Costa Gomes, M.; Pádua, A. A., Transferable, Polarizable Force Field for Ionic Liquids. J. Chem. Theory Comput. 2019, 15, 5858-5871.

57. Lopes, J. N. C.; Deschamps, J.; Padua, A. A. H., Modeling ionic liquids using a systematic all-atom force field. J. Phys. Chem. B 2004, 108, 2038-2047.

58. Lopes, J. N. C.; Padua, A. A. H., Molecular force field for ionic liquids III: Imidazolium, pyridinium, and phosphonium cations; Chloride, bromide, and dicyanamide anions. J. Phys. Chem. B 2006, 110, 19586-19592.

59. Jorgensen, W. L.; Maxwell, D. S.; TiradoRives, J., Development and testing of the OPLS all-atom force field on conformational energetics and properties of organic liquids. J. Am. Chem. Soc. 1996, 118, 11225-11236.

60. Jorgensen, W. L.; Tirado-Rives, J., Potential energy functions for atomic-level simulations of water and organic and biomolecular systems. Proc Natl Acad Sci U S A 2005, 102, 66656670.

61. Dodda, L. S.; Vilseck, J. Z.; Tirado-Rives, J.; Jorgensen, W. L., $1.14 *$ CM1A-LBCC: Localized Bond-Charge Corrected CM1A Charges for Condensed-Phase Simulations. J. Phys. Chem. B 2017, 121, 3864-3870.

62. Dodda, L. S.; de Vaca, I. C.; Tirado-Rives, J.; Jorgensen, W. L., LigParGen web server: an automatic OPLS-AA parameter generator for organic ligands. Nucleic Acids Res 2017, 45, W331W336.

63. Heid, E.; Szabadi, A.; Schröder, C., Quantum mechanical determination of atomic polarizabilities of ionic liquids. Phys. Chem. Chem. Phys. 2018, 20, 10992-10996.

64. fftool. https://github.com/agiliopadua/fftool (accessed 7 April 2020).

65. Zeman, J.; Uhlig, F.; Smiatek, J.; Holm, C., A coarsegrained polarizable force field for the ionic liquid 1-butyl-3methylimidazolium hexafluorophosphate. J. Phys. Condens. Matter 2017, 29, 504004. 
66. pol_il. https://github.com/agiliopadua/pol il (accessed 7 April 2020).

67. Brehm, M.; Kirchner, B., TRAVIS-a free analyzer and visualizer for Monte Carlo and molecular dynamics trajectories. J. Chem. Inf. Model. 2011, 51, 2007-2023.

68. Chung, L. W.; Sameera, W.; Ramozzi, R.; Page, A. J.; Hatanaka, M.; Petrova, G. P.; Harris, T. V.; Li, X.; Ke, Z.; Liu, F., The ONIOM method and its applications. Chem. Rev 2015, 115, 56785796.

69. Zhao, Y.; Truhlar, D. G., The M06 suite of density functionals for main group thermochemistry, thermochemical kinetics, noncovalent interactions, excited states, and transition elements: two new functionals and systematic testing of four M06class functionals and 12 other functionals. Theor. Chem. Acc. 2008, 120, 215-241.

70. Weigend, F.; Ahlrichs, R., Balanced basis sets of split valence, triple zeta valence and quadruple zeta valence quality for $\mathrm{H}$ to Rn: Design and assessment of accuracy. Phys Chem Chem Phys 2005, 7, 3297-3305.

71. Stewart, J. J., Optimization of parameters for semiempirical methods VI: more modifications to the NDDO approximations and re-optimization of parameters. J. Molec. Modeling 2013, 19, 1-32.

72. Xu, L.; Coote, M. L., Methods To Improve the Calculations of Solvation Model Density Solvation Free Energies and Associated Aqueous p K a Values: Comparison between Choosing an Optimal Theoretical Level, Solute Cavity Scaling, and Using Explicit Solvent Molecules. J. Phys. Chem. A 2019, 123, 7430-7438.

73. Xu, L.; Coote, M. L., Improving the Accuracy of PCMUAHF and PCM-UAKS Calculations Using Optimized Electrostatic Scaling Factors. J. Chem. Theory Comput. 2019, 15, 6958-6967.

74. Riplinger, C.; Neese, F., An efficient and near linear scaling pair natural orbital based local coupled cluster method. $J$ Chem Phys 2013, 138, 034106.

75. Wylie, L.; Oyaizu, K.; Karton, A.; Yoshizawa-Fujita, M.; Izgorodina, E. I., Toward improved performance of all-organic nitroxide radical batteries with ionic liquids: a theoretical perspective. ACS Sustain Chem Eng 2019, 7, 5367-5375.

76. Humphrey, W.; Dalke, A.; Schulten, K., VMD: visual molecular dynamics. J. Molec. Graphics 1996, 14, 33-38.
77. Cassone, G.; Giaquinta, P. V.; Saija, F.; Saitta, A. M., Liquid methanol under a static electric field. J. Chem. Phys. 2015, 142,054502

78. Seeger, Z. L.; Kobayashi, R.; Izgorodina, E. I., Cluster approach to the prediction of thermodynamic and transport properties of ionic liquids. J. Chem. Phys 2018, 148, 193832.

79. Sharma, P.; Bhatti, T., A review on electrochemical double-layer capacitors. Energy Convers. Manag 2010, 51, 29012912.

80. Futamura, R.; liyama, T.; Takasaki, Y.; Gogotsi, Y.; Biggs, M. J.; Salanne, M.; Segalini, J.; Simon, P.; Kaneko, K., Partial breaking of the Coulombic ordering of ionic liquids confined in carbon nanopores. Nat. Mater. 2017, 16, 1225-1232.

81. Kondrat, S.; Kornyshev, A., Superionic state in doublelayer capacitors with nanoporous electrodes. J. Phys. Condens. Matter 2010, 23, 022201.

82. IQmol. http://iamol.org/ (accessed 23 May 2020).

83. Lakowicz, J. R., Dynamics of Solvent and Spectral Relaxation. In Principles of Fluorescence Spectroscopy, Lakowicz, J. R., Ed. Springer Boston, MA, 2006; pp 237-276.

84. Driver, G. W.; Huang, Y.; Laaksonen, A.; Sparrman, T.; Wang, Y. L.; Westlund, P. O., Correlated/non-correlated ion dynamics of charge-neutral ion couples: the origin of ionicity in ionic liquids. Phys. Chem. Chem. Phys. 2017, 19, 4975-4988.

85. Green, S. M.; Ries, M. E.; Moffat, J.; Budtova, T., NMR and Rheological Study of Anion Size Influence on the Properties of Two Imidazolium-based Ionic Liquids. Sci. Rep. 2017, 7, 8968.

86. Nishi, N.; Hirano, Y.; Motokawa, T.; Kakiuchi, T., Ultraslow relaxation of the structure at the ionic liquid/gold electrode interface to a potential step probed by electrochemical surface plasmon resonance measurements: asymmetry of the relaxation time to the potential-step direction. Phys. Chem. Chem. Phys. 2013, 15, 11615-11619.

87. Bruce, D. W.; Gao, Y. A.; Lopes, J. N. C.; Shimizu, K.; Slattery, J. M., Liquid-Crystalline Ionic Liquids as Ordered Reaction Media for the Diels-Alder Reaction. Chem.-Eur. J. 2016, 22, $16113-$ 16123. 
TOC Graphic:

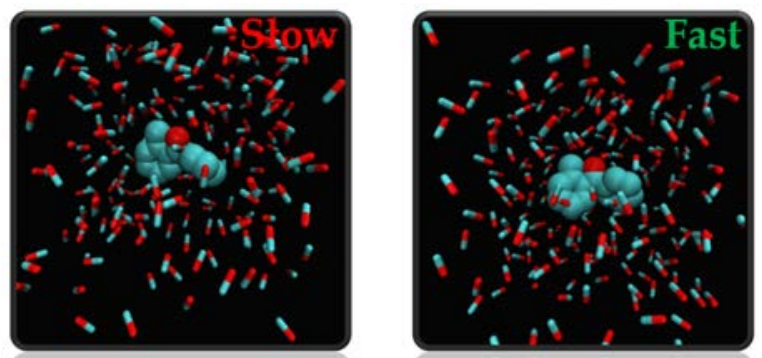

Order Is Power 